\title{
DIGITAL

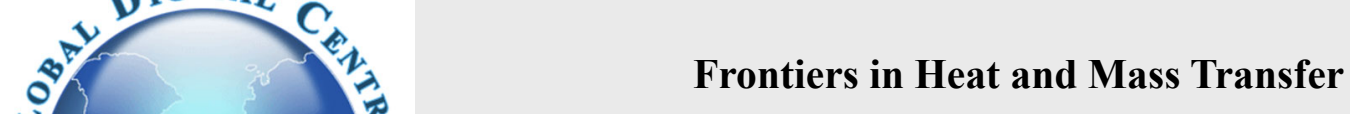 \\ THERMAL ANALYSIS OF HEAT TRANSFER ENHANCEMENT OF RIB HEAT SINK FOR CPU
}

\author{
Ming Zhao*, Yang Tian \\ College of Energy and Power Engineering, University of Shanghai for Science and Technology, Shanghai, 200093, China
}

\begin{abstract}
The field synergy principle and thermal resistance analysis were carried out for the heat transfer enhancement of a chip heat sink. Thermal analysis of the heat dissipation capacity is applied for setting up the gallery on the rib, changing the fan ventilation diameter, and changing the rib height. The results show that the analysis of field synergy principle agrees well with that of the thermal analysis, and setting up a gallery on the rib can improve the heat capacity of the heat sink. Meanwhile, the results also show that decreasing diameter of the ventilation causes heat capacity dropping because the reverse flow area increases and the air flow rate reduces. Furthermore, the rib height plays an important role in the flow path geometry, and it has a significant effect on the convective heat transfer coefficient.
\end{abstract}

Keywords Thermal resistance analysis, numerical simulation, field synergy

\section{INTRODUCTION}

The Central Processing Unit (CPU) is responsible for processing most of the data in modern computing systems involving a personal computer, and it generates the most amount of heat in the system. According to the statistics, the failure of electronic equipment is often manifested in its long-term work in the overheated state. In order to ensure reliable operations, the thermal design of personal computer (PC) or electronic devices must be applied in allowable temperature ranges.

There are many techniques to dissipate the generated heat. Despite of the rapid development of mini and micro-components and liquid based cooling, air-cooling is still the most common used method for thermal management of computer chips nowadays. Heat is transported from the chip to an adjacent metal rib heat sink and then transferred to the surrounding air. Although there have been many research work about aircooling, there are still a lot of challenges in the applications of new technology, new structures, and new materials.

Many researchers investigated the enhancement design or calculation of different heat sinks using numerical and experimental methods. Bejan and Sciubba (1992) obtained the optimal rib spacing for maximum heat transfer from a package of parallel plates that was cooled by forced convection. Knight et al. (1992) developed a rib optimization method for a heat sink with micro channels by iterative solution of nonlinear equations. Bessaih and Kadja (2000) carried out the numerical simulation of air turbulence on several electronic components in a vertical channel, and the influence of the heat dissipation of the components was obtained and a method of heat dissipation was proposed. Etemoglu (2007) had experimented with and analyzed the new technologies of cooling the electronic equipment such as jet-flow and micro-channel and obtained some practical and useful conclusions. Ozturk and Tari (2008) had performed a numerical simulation of the air cooling CPU heat sink. Yang and Peng (2008) used in the case of nonuniform rib height. Naphon et al. (2009a, 2009b) reported the CPU liquid-cooled micro-rib heat sink numerical analysis. Mohan and Govindarajan (2011) performed experimental and theoretical investigations of the thermal performance of various finned heat sinks; the experimental results of several of heat sinks with simple geometry had been compared to those predicted by Fluent. The parameters such as fin geometry, fin pitch and fin height were optimized. Baby and Balaji (2013) employed experimental methods to optimize the thermal performance of rib heat sinks with phase change materials. Chen et al. (2013) carried out a variety of optimization on the plate ribs heat sink. Levin et al. (2013) presented an optimization procedure for the design of a Latent Heat Thermal Management System (LHTMS), which was used for cooling an electronic device with transient and high heat generation. Yamamoto et al. (2014) applied fine mist cooling as a high heat removal technology to the cooling of a high temperature work material.

Most recently, Hamdi (2016) applied numerical simulation about the thermal design of PFHS (Ribbed Flat-Plate Fin Heat Sink) by inserting ribs between channels in different sizes, positions, numbers, and orientations in order to get an optimal thermal design of this kind of heat sinks. Ghasemi et al. (2017) experimentally studied thermal and hydraulic performances of heat sinks with various channel diameters for cooling electronic components. Huang et al. (2017) aimed at developing the structures of micro-channel heat sinks for chip cooling techniques, and numerically studied three types of slotted micro-channel heat sinks with metal-foam inlet header. Joo et al. (2017) studied the heat sinks in natural convection which were thermally optimized by using the topology optimization method. Yang et al. (2017) scheduled an experimental plan for the parameters optimization of PFCHS (pin-fins 
channel heat sink) based on the uniform design.

The field synergy principle proposed by Guo et al. (2000a, 2005b) indicates that the heat transfer rate depends not only on the flow and temperature fields but also on their synergy. The principle of field synergy for the enhancement of convective heat transfer may be stated as follows: the better the synergy of velocity and temperature gradient/heat flow fields, the higher the convective heat transfer rate under the same other conditions. The field synergy principle has attracted a wide range of interests from researchers.

The objective of this paper is to apply the field synergy principle and thermal resistance analysis for the enhancement of air-cooling based heat sink of CPU. The CFD software ANSYS FLUENT are used to carry out thermal analysis of the heat dissipation capacity change caused by (1) setting up the gallery on the rib, (2) changing the fan ventilation diameter and (3) changing the rib height.

\section{PHYSICAL AND MATHEMATICAL MODEL}

\subsection{Physical model}

Figure 1 shows a simplified schematic representation of a straight rib heat sink for a small chip (Modeled in Fluent). Chip slot area is at the bottom, where is the heating surface. The geometric dimensions of the fan inlet surface and ribs are derived from an actual CPU cooler and the technical parameters of an ATC fan. The heat sink has two rows of ribs, the size of each rib is 32 (height) $\times 36$ (length) $\times 0.8$ (thickness) $\mathrm{mm}$. In order to simplify the physical model, two half of the rib are considered in the model. The rib spacing is $1.75 \mathrm{~mm}$ and the rib base thickness is $6 \mathrm{~mm}$. In order to analyze the effect of the gallery on the heat dissipation capacity, two models are presented in Fig. 1: (1) no gallery on the rib, as shown in Fig. 1 (a); (2) gallery on the rib, as shown in Fig. 1 (b).

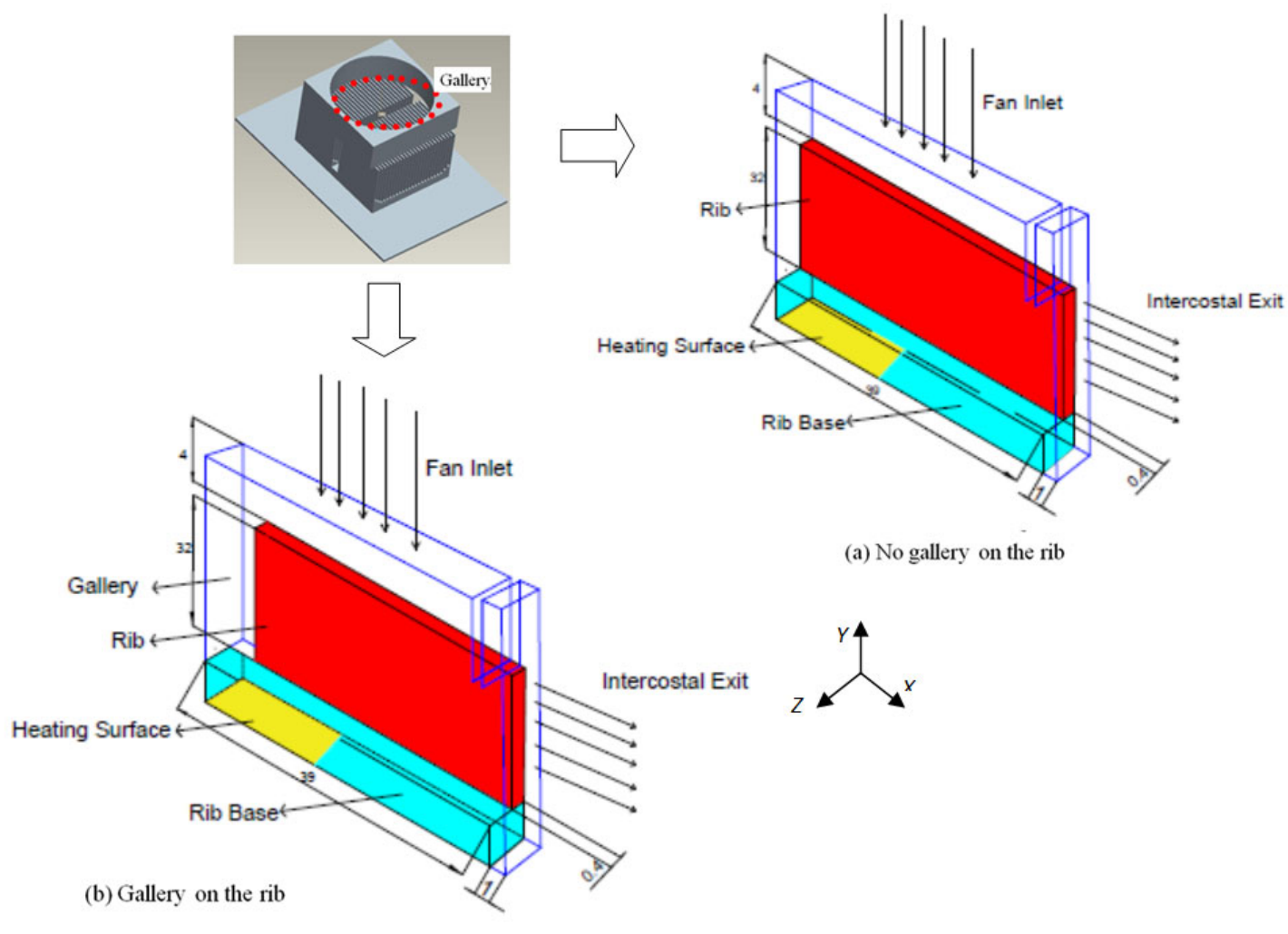

Fig. 1 The physical model of the CPU heat sink (Modeled in Fluent)

\subsection{Mathematical model}

The problem under consideration is a fluid-solid coupling problem. According to the flow and heat transfer characteristics of the problem, the convective model is assumed as follows:

(1) The fluid in the space is Boussinesq fluid.

(2) The convective heat transfer between the rib base and the circuit board is zero, which is an adiabatic face. The air here and the wind blown by the fan are located on each side of the rib base, and its surrounding flow state is symmetrical. The volume is also very small and the air here can hardly flow, so that the heat transfer is very small and it can be ignored.

(3) The temperature gradient in the thickness direction of the ribs is zero; since the ribs are very thin, this can simplify the computational grids of the ribs.

(4) As a result of the structure in the flow path where the velocity direction is abruptly changed, the fluid of the different layers is blended with each other, so the turbulence model is used to simulate the fluid zone.

Assuming that flow and heat transfer are three-dimensional, steadystate turbulent forced convection heat transfer, the standard $k-\varepsilon$ twoequation model is employed. In addition, the solid heat conduction model is three-dimensional and steady-state.

The governing equations can be written as follows:

The solid zone:

The energy equation is: 


$$
\frac{\partial^{2} T}{\partial \mathrm{x}^{2}}+\frac{\partial^{2} T}{\partial \mathrm{y}^{2}}+\frac{\partial^{2} T}{\partial \mathrm{z}^{2}}=0
$$

which is subject to the following boundary conditions:

Heating flux:

$$
\lambda_{\mathrm{s}} \frac{\partial T}{\partial \mathbf{n}}=29720 \mathrm{~W} \square \mathrm{m}^{-2}
$$

Adiabatic face:

$$
\partial T / \partial \mathbf{n}=0
$$

Symmetrical face:

$$
\partial T / \partial \mathbf{n}=0
$$

Intersection face with fluid:

$$
T_{\mathrm{s}}=T_{\mathrm{a}}
$$

The fluid zone:

Continuity Equation is:

$$
\frac{\partial u}{\partial \mathrm{x}}+\frac{\partial v}{\partial \mathrm{y}}=0
$$

Momentum Equations are:

$$
\begin{aligned}
& \frac{\partial(\rho u)}{\partial t}+\frac{\partial(\rho u u)}{\partial \mathrm{x}}+\frac{\partial(\rho u v)}{\partial \mathrm{y}}=\frac{\partial}{\partial \mathrm{x}}\left(\eta \frac{\partial u}{\partial \mathrm{x}}\right)+\frac{\partial}{\partial \mathrm{y}}\left(\eta \frac{\partial u}{\partial \mathrm{y}}\right)+S_{u} \\
& \frac{\partial(\rho v)}{\partial t}+\frac{\partial(\rho u v)}{\partial \mathrm{x}}+\frac{\partial(\rho v v)}{\partial \mathrm{y}}=\frac{\partial}{\partial \mathrm{x}}\left(\eta \frac{\partial v}{\partial \mathrm{x}}\right)+\frac{\partial}{\partial \mathrm{y}}\left(\eta \frac{\partial v}{\partial \mathrm{y}}\right)+S_{v}
\end{aligned}
$$

where:

$$
\begin{gathered}
S_{u}=-\frac{\partial \rho}{\partial \mathrm{x}}+\frac{\partial}{\partial \mathrm{x}}\left(\eta_{\mathrm{t}} \frac{\partial u}{\partial \mathrm{x}}\right)+\frac{\partial}{\partial \mathrm{y}}\left(\eta_{\mathrm{t}} \frac{\partial v}{\partial \mathrm{y}}\right) \\
S_{v}=-\frac{\partial \rho}{\partial \mathrm{y}}+\frac{\partial}{\partial \mathrm{x}}\left(\eta_{\mathrm{t}} \frac{\partial u}{\partial \mathrm{y}}\right)+\frac{\partial}{\partial \mathrm{y}}\left(\eta_{\mathrm{t}} \frac{\partial v}{\partial \mathrm{y}}\right)-g \rho\left[1-\beta\left(T-T_{\mathrm{c}}\right)\right]
\end{gathered}
$$

Energy equation is:

$$
\frac{\partial(\rho T)}{\partial t}+\frac{\partial(\rho u T)}{\partial \mathrm{x}}+\frac{\partial(\rho u T)}{\partial \mathrm{y}}=\frac{\partial}{\partial \mathrm{x}}\left(\Gamma \frac{\partial T}{\partial \mathrm{x}}\right)+\frac{\partial}{\partial \mathrm{y}}\left(\Gamma \frac{\partial T}{\partial \mathrm{y}}\right)+S_{\mathrm{T}}
$$

where:

$$
\begin{gathered}
\Gamma=\frac{\eta}{P r}+\frac{\eta_{\mathrm{t}}}{\sigma_{\mathrm{t}}} \\
S_{\mathrm{T}}=\eta\left\{2\left[\left(\frac{\partial u}{\partial \mathrm{x}}\right)^{2}+\left(\frac{\partial v}{\partial \mathrm{y}}\right)^{2}\right]+\left(\frac{\partial u}{\partial \mathrm{x}}+\frac{\partial v}{\partial \mathrm{y}}\right)^{2}\right\}
\end{gathered}
$$

$k-\varepsilon$ turbulent model equations are:

$k$ or Turbulent kinetic energy equation is:

$$
\begin{aligned}
& \frac{\partial(\rho k)}{\partial t}+\frac{\partial(\rho u k)}{\partial \mathrm{x}}+\frac{\partial(\rho v k)}{\partial \mathrm{y}}=\frac{\partial}{\partial \mathrm{x}}\left[\left(\eta+\frac{\eta_{\mathrm{t}}}{\sigma_{k}}\right) \frac{\partial k}{\partial \mathrm{x}}\right]+ \\
& \frac{\partial}{\partial \mathrm{y}}\left[\left(\eta+\frac{\eta_{\mathrm{t}}}{\sigma_{k}}\right) \frac{\partial k}{\partial \mathrm{y}}\right]+\rho G_{k}-\rho \varepsilon
\end{aligned}
$$

$\varepsilon$ or turbulent kinetic energy dissipation rate equation is:

$\frac{\partial(\rho \varepsilon)}{\partial t}+\frac{\partial(\rho u \varepsilon)}{\partial \mathrm{x}}+\frac{\partial(\rho v \varepsilon)}{\partial \mathrm{y}}=\frac{\partial}{\partial \mathrm{x}}\left[\left(\eta+\frac{\eta_{\mathrm{t}}}{\sigma_{\varepsilon}}\right) \frac{\partial \varepsilon}{\partial \mathrm{x}}\right]+$

$$
\frac{\partial}{\partial \mathrm{y}}\left[\left(\eta+\frac{\eta_{\mathrm{t}}}{\sigma_{\varepsilon}}\right) \frac{\partial \varepsilon}{\partial \mathrm{y}}\right]+\frac{\varepsilon}{k}\left(c_{1} \rho G_{k}-c_{2} \rho \varepsilon\right)
$$

where:

$$
\begin{aligned}
& G_{k}=\frac{\eta_{\mathrm{t}}}{\rho}\left\{2\left[\left(\frac{\partial u}{\partial x}\right)^{2}+\left(\frac{\partial v}{\partial \mathrm{y}}\right)^{2}\right]+\left(\frac{\partial u}{\partial \mathrm{x}}+\frac{\partial v}{\partial \mathrm{y}}\right)\right\} \\
& \eta_{\mathrm{t}}=c_{\mu} \rho \frac{k^{2}}{\varepsilon}
\end{aligned}
$$

The constants among the above equations are (Versteeg and Malalasekera, 1995):

$c_{\mu}=0.009, c_{1}=1.44, c_{2}=1.92, \sigma_{k}=1.0, \sigma_{\varepsilon}=1.3, \sigma_{\tau}=0.9-1.0$.

Boundary conditions are:

Fan inlet face: $u_{\mathbf{n}}=4.139 \mathrm{~m} \cdot \mathrm{s}^{-1}, T=300 \mathrm{~K}$.

Adiabatic face: $u_{\mathrm{x}}=u_{\mathrm{y}}=u_{\mathrm{z}}=0, \partial T / \partial \mathbf{n}=0$.

Symmetrical face: $\partial T / \partial \mathbf{n}=\partial u_{\mathrm{x}} / \partial \mathbf{n}=\partial u_{\mathrm{y}} / \partial \mathbf{n}=\partial u_{\mathrm{z}} / \partial \mathbf{n}=\partial p / \partial \mathbf{n}=0$.

Intersection face with solid: $u_{\mathrm{x}}=u_{\mathrm{y}}=u_{\mathrm{z}}=0, T_{\mathrm{a}}=T_{\mathrm{s}}$.

Fluid outlet face: OUTFLOW or pressure outlet at $p=1.01 \times 10^{5} \mathrm{~Pa}$.

\subsection{Field synergy and heat transfer performance}

Field synergy principle was introduced for a 2-D boundary layer flow (Guo et al., 2005), and the energy equation is

$$
\rho c_{\mathrm{p}}\left(u \frac{\partial T}{\partial \mathrm{x}}+v \frac{\partial T}{\partial \mathrm{y}}\right)=\frac{\partial}{\partial \mathrm{y}}\left(k \frac{\partial T}{\partial \mathrm{y}}\right)
$$

The energy equation for conduction with a heat source is

$$
-\dot{q}=\frac{\partial}{\partial \mathrm{y}}\left(\frac{\partial T}{\partial \mathrm{y}}\right)
$$

From Eqs. (17) and (18), it can be seen that the convection term in the energy equation for the boundary layer flow corresponds to the heat source term in the conduction equation. Meanwhile, the integral of Eq. (17) over the thickness of the thermal boundary layer can be rewritten with the convection term in vector form as

$$
\int_{0}^{\delta_{t}} \rho c_{p}(U \bullet \nabla T) d y=-\left.k \frac{\partial T}{\partial y}\right|_{\delta_{t}}
$$

where $\delta_{\mathrm{t}}$ is the thickness of thermal boundary layer.

With the following dimensionless variables for the boundary layer flow,

$$
\bar{U}=\frac{U}{U_{\infty}}, \quad \nabla \bar{T}=\frac{\nabla T}{\left(T_{\infty}-T_{w}\right) / \delta_{t}}, \quad \bar{y}=\frac{y}{\delta_{t}}
$$

Equation (19) can be written in the following dimensionless form

$$
\mathrm{Nu}_{x}=\operatorname{Re}_{x} \operatorname{Pr} \int_{0}^{1}(\bar{U} \bullet \nabla \bar{T}) d \bar{y}
$$

The vector dot product in the dimensionless integration in Eq. (21) can be expressed as

$$
\bar{U} \bullet \nabla \bar{T}=|\bar{U}||\nabla \bar{T}| \cos \beta
$$

where $\beta$ is the included angle between the velocity vector and the 
temperature gradient (heat flow vector).

Equations (19) and (22) show that the velocity vector and the temperature gradient, or the angle between the velocity vector and the heat flow vector, are important for the size of the heat source or the intensity of convective heat transfer. When their angle is less than $90^{\circ}$, the convective heat transfer coefficient increases as $\beta$ decreases. When $\beta=0^{\circ}$, the maximum value can be reached. Meng (2003) pointed out through analysis that the field synergy principle is also applicable to 3-D steady-state flow.
In this paper, the geometric shape of the computational model and the direction of the fluid inlet and outlet are fairly regular, so hexahedral meshes are employed in the numerical simulation. The fluid has lower heat capacity, and greater changes of the physical properties than the solid, so more grids with smaller size are required for flow calculation in the fluid zone. In addition, because of the influence of the boundary layer, more grids are also needed in the near-wall area. Boundary layer division can be achieved through the use of FLUENT. Grid assessment results are shown in Table 1.

\subsection{Numerical procedure and code validation}

Table 1 Grid assessment

\begin{tabular}{lllll}
\hline Grid partition & 1 & 2 & 3 & 4 \\
\hline Fluid computational domain:grid size & 0.5 & 0.4 & 0.3 & 0.25 \\
Thickness of the first layer of the boundary layer & 0.1 & 0.1 & 0.1 & 0.05 \\
Number of grids & 32094 & 49424 & 86023 & 150680 \\
Solid computational domain:grid size & 0.5 & 0.5 & 0.5 & 0.5 \\
Number of grids & 10842 & 16954 & 29999 & 70824 \\
Maximum temperature of the solid domain $(\mathrm{K})$ & 311.59 & 312.06 & 312.68 & 312.3 \\
Average temperature of the heating surface & 311.13 & 311.56 & 312.17 & 311.77 \\
Maximum velocity of fluid domain $\left(\mathrm{m} \cdot \mathrm{s}^{-1}\right)$ & 11.21 & 11.35 & 11.35 & 11.66 \\
\hline
\end{tabular}

As can be seen in Table 1, with the grid size gradually increased, changes in grid partition 2 and partition 3 are both within the range of $5 \%$. Considering the economy of the calculation, the grid partition 2 is chosen for the numerical solution.

The validation of the computer code is performed by comparing the rib efficiency with the theoretical results (Yang and Tao, 2006) (Fig. 2). It can be seen that the largest difference percentage is $2 \%$, the result shows a good agreement.

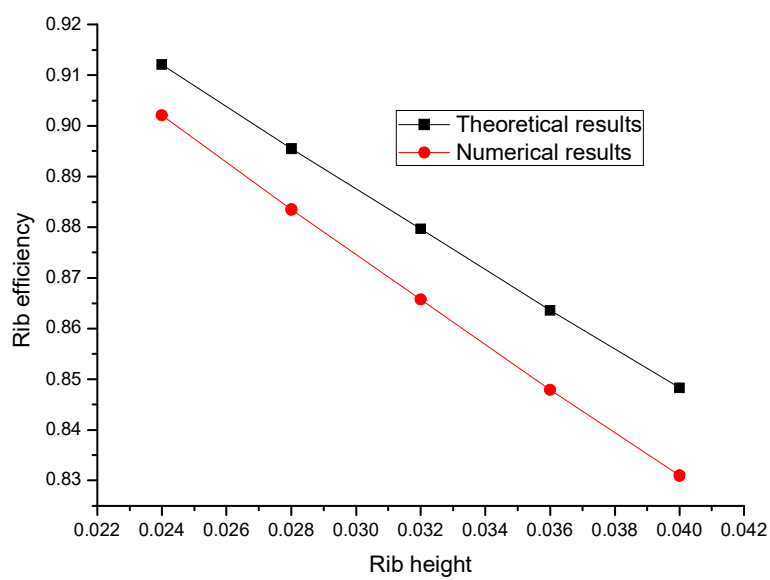

Fig. 2 Comparison of the results for validation with the theoretical results

\section{RESULTS AND DISCUSSIONS}

\subsection{Effects of gallery opened between ribs on the heat sink}

Two models (no gallery on the rib, shown in Fig. 1(a) and gallery on the rib, shown in Fig. 1(b)) are numerically studied. The gallery in width of $3 \mathrm{~mm}$ is opened up in the symmetry of the ribs. Since the state parameters between the two rows of ribs are not easily determined, we only know that the outermost two rows of the channel exits are at the environmental temperature; it is assumed that the boundary conditions of the gallery on the ribs are also at same conditions as the other outlets. This is equivalent to assume that the fluid flowing into the intercostal channel will flow directly into the environment without interfering with each other, which is the limit of the maximum heat dissipation capability of a single rib in the vertical fan.

The numerical results are shown in Figs. 3 and 4. Figure 3(a) shows the temperature field and velocity field of no gallery on the rib; Figure 3(b) shows the temperature field and velocity field of the gallery on the rib. Figure 4 shows the comparisons of the coefficient. It can be obtained that, after adding a gallery, the maximum temperature of the solid region $(\mathrm{z}=0)$ is $313.88 \mathrm{~K}$, and the average temperature of the heating surface is $313.08 \mathrm{~K}$; the maximum velocity of the fluid region $(\mathrm{z}=1.2)$ is $7.7 \mathrm{~m} \cdot \mathrm{s}$ ${ }^{1}$. The maximum surface convection heat transfer coefficient is 123.5 $\mathrm{W} \cdot \mathrm{m}^{-2} \cdot \mathrm{k}^{-1}$, and the minimum surface convection coefficient is close to zero. The average temperature of the heating surface and the maximum temperature of the solid part are slightly higher than the original temperatures. The convective heat transfer coefficient of the symmetry plane of the ribs is higher than that of the original case, and both gradually decrease from the top of the ribs to the bottom of ribs. 


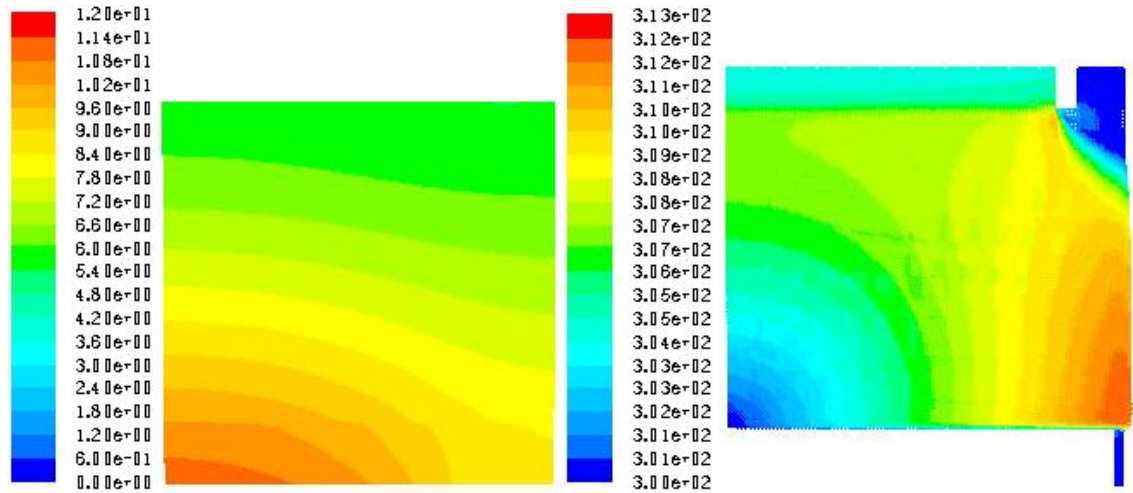

(a) No gallery on the rib, left: Temperature field at $z=0$, right: the velocity field at $z=1.2$
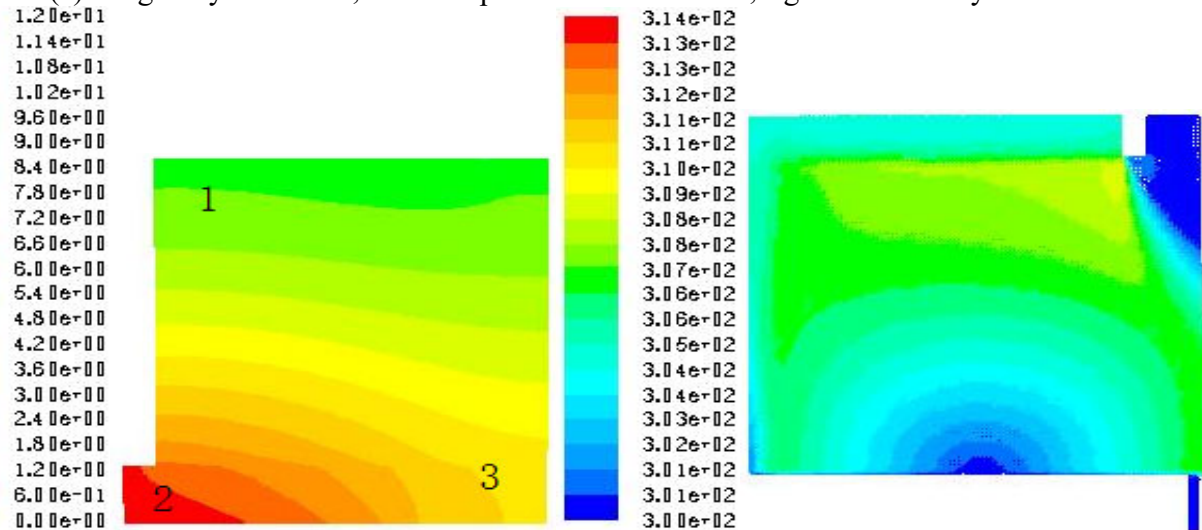

(b) Gallery on the rib, left: Temperature field at $\mathrm{z}=0$, right: the velocity field at $\mathrm{z}=1.2$

Fig. 3 Comparisons of temperature field and velocity field (a) with no gallery, (b) with gallery

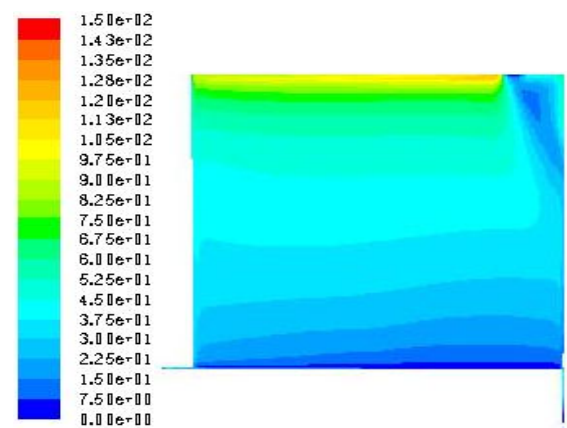

(a) With gallery

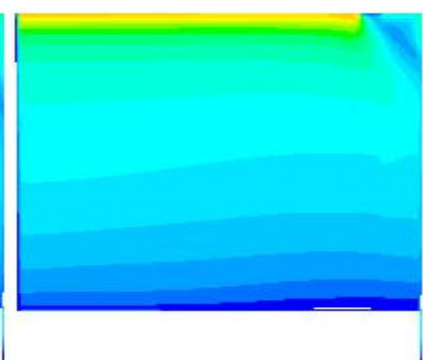

(b) Without gallery

Fig. 4 Comparison of surface convection heat transfer coefficients before and after opening gallery

First of all, because the air is blowing down vertically, it directly plays a role in enhancing heat transfer. According to the Fourier heat conduction law, the heat conduction of the heat sink under the same surface heat transfer coefficient can result in the temperature distribution of the ribs and the rib base is $t_{2}>t_{3}>t_{1}$ (Fig. 3). It is derived from $t_{2}>t_{1}$ that the heat transfer process of the vertical downward blow is a counter current heat transfer process, and the temperature of the wind near the rib base can be higher than that near the top of the rib (still lower than the temperature of any point on the surface of the rib base). It can take more heat away than the air flow whose direction is vertical upward (downstream heat transfer). If the air blows the ribs horizontally, only when the air is close to the rib base can take heat away.

The velocity field of the fluid before and after opening gallery in this region can also be directly compared (Fig. 3). It can be found that the velocity of the fluid near the plane of its symmetry is significantly higher than that of the original case especially in the part close to the rib base, which improves the surface convective heat transfer coefficient here, and also increases the air flow on the parts of the heat sink where the heat is high. And the velocity here is almost zero before the gallery is added.

The surface convective heat transfer coefficient gradually decreases from top to bottom because of the developments of the velocity and temperature boundary layer. In the flow direction of the fluid, the velocity and temperature boundary layers become thicker, and the thickened boundary layer leads to an increase in the area of convection in the fluid region and a decrease in heat flow per unit area; this also reduces the surface convective heat transfer coefficient. While the velocity of the velocity boundary layer is the same as its upstream velocity, the temperature gradient in the boundary layer is lower than the upstream, which also results in a low convective heat transfer coefficient. The converse is the surface heat transfer coefficient at the inlet end of the ribs can be as high as $123.5 \mathrm{~W} \cdot \mathrm{m}^{-2} \cdot \mathrm{k}^{-1}$. 
The convective heat transfer coefficient in the upper right corner of the rib is very low due to the low velocity of the fluid near the air inlet. At the same time, the increase in fluid velocity in a region also enhances the fluid flow and can remove more heat in the same time. In addition, during the air blowing to the rib base, the core area of the velocity quickly reduces to nearly zero due to the obstruction of the wall and the growth of the boundary layer; so that the convective heat transfer coefficient gradually reduces to zero.

In the direction of flow, the fluid in the heat sink enters from the same inlet and flows out of the channels between the ribs and between the rows of ribs. It can be found that the fluid flowing from the intermediate passage near the rib base portion can be exchanged heat with more rib base surfaces (with heating surfaces at the bottom) where the temperature is high. At the boundary layer, since there is no wall on the channels, the boundary layers do not become too thick when the fluid reaches the surfaces of the ribs, so the convective coefficient on the surface near the rib of the symmetry plane of the heat sink is relatively large.

Considering the above mentioned three factors, it is not difficult to find the effect of opening a gallery. The same effect of the three factors is to strengthen the heat transfer in the high temperature part of the ribs, while it also reduces the heat transfer at the outlet between the low temperature parts of the ribs.

Figure 5 shows the contour of the field synergy angle for this case. One can see that opening a gallery can decrease the field synergy angle of the exit and the fluid field. The average field synergy angle of the flow field reduced from $78.15^{\circ}$ to $76.49^{\circ}$, the coordination has improved significantly. The improvement of the field synergy can enhance the convective heat transfer of the fluid area, improve the heat transfer intensity and strengthen the heat dissipation process. However, as shown in Fig. 5, for the low-temperature area near the outlet, the synergy is significantly decreased, and the heat transfer intensity is decreased. The analysis of field synergy mutually confirmed the above thermal analysis.
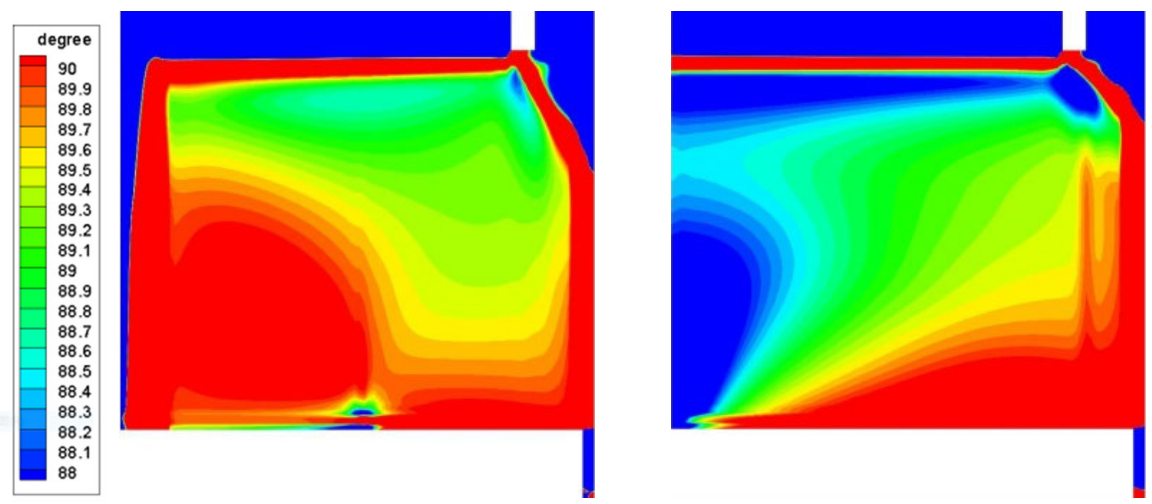

Fig. 5 Contour of field synergy angle, left: solid field at $\mathrm{z}=0$, right: fluid field at $\mathrm{z}=1.2$

\subsection{Effects of fan ventilation diameter on the heat dissipation}

In the actual work of the heat sink, air does not uniformly flow through the ribs, but more in the middle part and less on the two sides. The influence of the fan diameter on the heat dissipation performance of the heat sinks is analyzed.

The air inlet diameter is decreased from $66 \mathrm{~mm}$ to $42 \mathrm{~mm}$, the numerical results are shown in Fig. 6 and Fig. 7. It can be obtained that the maximum temperature of the solid region is $313.74 \mathrm{~K}$, and the average temperature of the heating surface is $313.29 \mathrm{~K}$; the maximum velocity of the fluid region is $8.68 \mathrm{~m} / \mathrm{s}$. The maximum surface convection coefficient is $135 \mathrm{~W} \cdot \mathrm{m}^{-2} \cdot \mathrm{k}^{-1}$, and the minimum surface convection coefficient is close to zero. The average temperature of the heating surface and the maximum temperature of the solid region are higher than those in the original case (as shown in Table 1). Moreover, the convection heat transfer coefficient near the surface of the fan shell is low, but the temperature of the rib is obviously improved; the air temperature is quite high.
One can also observe that the velocity vector field of the fluid near the fan shell and the fluid close to the base surface portion (see the dashed box in Fig. 6(b)) is interesting. Although the velocities for both locations are very low, the reason is different. The fluid flowing around the fan shell is re-flowed due to the irregularity of the flowing geometric channel and forms a whirlpool. The velocity of the fluid near the rib base decreases and the direction of the movement changes, which is also because of the change of the geometric channel, instead of reflow. The convection heat transfer coefficient of the rib surface is very small due to the low velocity. The heated fluid does not flow out from the outlet easily due to the effect of reflow, and it goes back to the original fluid which is not heated and then mixes. This will lead to three results: (1) the convection heat transfer coefficient reduces because of the low velocity. (2) The heated fluid cannot flow out in time, and it results in the reflow zone of the fluid temperature increases; that is more detrimental to the region of the ribs of the heat dissipation. (3) The heated fluid flows back

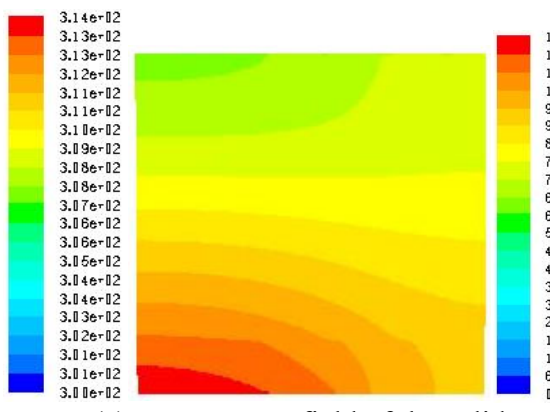

(a) Temperature field of the solid region $(\mathrm{z}=0)$

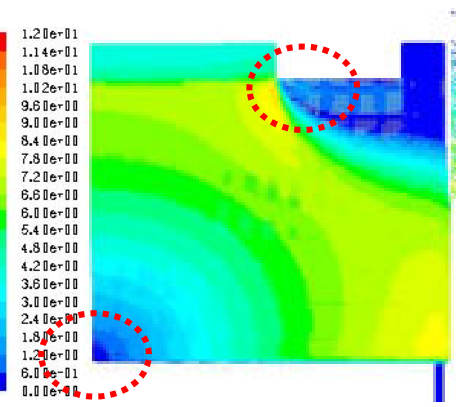

(b) The velocity field of the fluid region $(\mathrm{z}=1.2)$

Fig. 6 Temperature field of the solid region and velocity field of the fluid region on the symmetry plane 

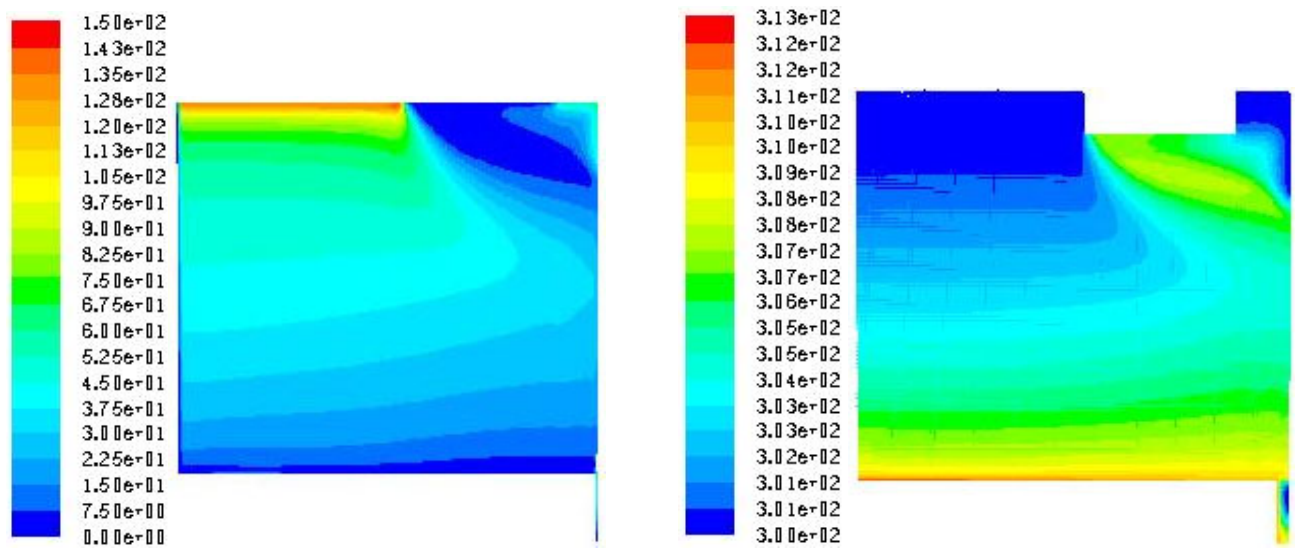

(a) Convection heat transfer coefficient distribution

(b) The temperature field of the fluid region on the symmetry plane distribution

Fig. 7 Convection heat transfer coefficient and the temperature field of the fluid region on the symmetry plane $(\mathrm{z}=1.2)$

to the fluid at lower temperature, which affects the heat transfer capacity of other parts. This shows that the reduction in the fan inlet diameter leads to an increase in the thickness of the shell, this will have an effect on heat dissipation, that is, reducing the flux of the fluid will cause increases of the reflow area.

When studying on the rib temperature distribution (Fig. 6(a)), we can obtain that the temperature gradient at the top of the ribs is significantly lower than that of the original case (Fig. 3(a)), but this does not improve the heat dissipation. Thermal resistance diagrams combined to analyze the reasons as follows (see Fig. 8).

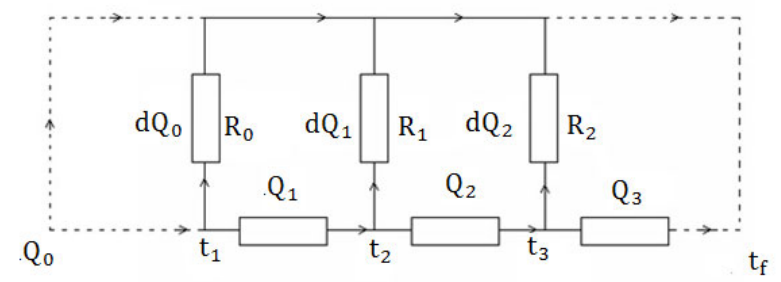

Fig. 8 Thermal resistance of the ribs

Since $\mathrm{R}_{2}$ (the thermal resistance of the part above the ribs and the thermal resistance of the air) increases, it is assumed that $\mathrm{Q}_{2}$ remains the same in the case that the other thermal resistances do not change. It is found that $\mathrm{dQ}_{2}$ becomes lower and $\mathrm{Q}_{3}$ increases; $\mathrm{t}_{2}$ increases by $\Delta \mathrm{t}_{2}$ while $\mathrm{t}_{3}$ increases by $\Delta \mathrm{t}_{3}$. Continue to reasoning, we can see that $\Delta \mathrm{t}_{2}$ (the increase in $t_{2}$ ) is equal to $\Delta t_{3}$, then $d_{Q_{1}}$ will increase. Since $\mathrm{Q}_{2}$ does not change, $\mathrm{Q}_{1}$ increases; then the increment $\Delta \mathrm{t}_{1}$ of $\mathrm{t}_{1}$ is greater than $\Delta \mathrm{t}_{2}$, and the increment $\mathrm{dQ}_{0}$ is greater than the increment $\mathrm{dQ}_{1}$. Therefore, the reason that the original reduction in temperature gradient can improve the cooling capacity is to reduce the thermal resistance, and here the air convection thermal resistance is increased, which causes the solid temperature gradient decrease, and the cooling capacity reduces.

In summary, reducing the ventilation diameter leads to the decrease of the radiating capacity, and the reason of which is the increase of the reflow area and the reduction of air flow. In the design of the actual heat sink, it is necessary to account for the influence of the reflow caused by the thickness of the fan shell, so as to adopt a better design method of the rib duct.

Figure 9 shows the contour of the field synergy angle for this case. One can see from Fig. 9, with the decrease of the inlet diameter, the fluid field synergy angle rises obviously, the fluid field average field synergy angle increased from $78.15^{\circ}$ and $81.16^{\circ}$, the coordination decreased obviously. The decrease of synergistic property affects the convection heat transfer in the fluid area, reduces the heat dissipation intensity and is not conducive to heat exchange. The analysis of field synergy is consistent with the results of the previous thermal analysis.

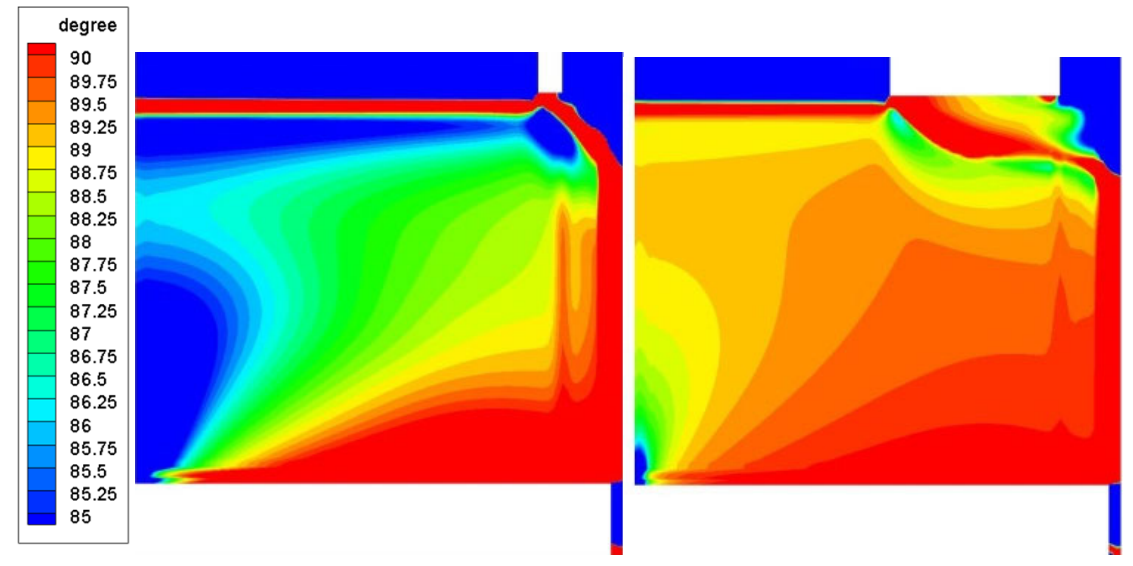

Fig. 9 Contour of field synergy angle, left: original case, right: smaller ventilation diameter 


\subsection{Effects on the heat sink heat dissipation by changing the rib height}

In the theoretical analysis of the rib heat conduction, the actual heat dissipation of the straight ribs of equal section is equal to the amount of heat dissipation of the entire rib at the rib base temperature multiplied by the rib efficiency, and meets with the functional formula of $\Phi=f\left(h, \lambda, b, \delta, t_{0}-t_{\mathrm{f}}\right)$. If the other conditions remain unchanged, only when $m h<3\left(m=\frac{h P}{\lambda_{\mathrm{s}} A_{c}}\right)$, where $h$ is the surface convection heat transfer coefficient, $P$ is heated circumference, $\lambda_{\mathrm{s}}$ is the thermal conductivity of the rib, $A_{c}$ is the rib cross-sectional area, the heat flux $\Phi$ may increase with the increase of $h$; so the rib height has an optimal value, not the higher the better. The results of numerical calculation with different rib heights are shown in Fig. 10 and Table 2.

As can be seen from Table 2, with the increase of the rib height, the maximum temperature of the solid region and the average temperature of the heating surface decrease slightly; meanwhile, the rib efficiency and the surface average heat transfer coefficient also decrease. In theory, when increasing the rib height to improve the heat transfer area, the maximum value of the rib height is derived from the analysis of the heat conduction theory. Since the increase in rib height will increase the thermal resistance along the height direction of the ribs and when the thermal resistance along this direction increases to a certain extent, it will be equal to or less than the convective heat transfer resistance of the rib surface. If the rib height is increased continually, the heat flux will not increase but will decrease. It can be seen that the optimal rib height is obtained by assuming that the average heat transfer coefficient of the surface is constant, so when the rib height increases, we only needs to consider the relationship between the reduction of the rib efficiency and the increase in the heat transfer area. However, under the premise of keeping the air volume unchanged, the rib height is obviously an important parameter that affects the surface heat transfer coefficient. The higher the rib height is, the lower the average heat transfer coefficient is. Firstly, it will waste material, That is to say, increasing a large number of ribs can only increase a small amount of heat dissipation. Secondly, it will make the forced convection of the fan do not play a role on the rib surface, but only play a role of forced convection near the fan, which is a waste of the kinetic energy of the fan. Thirdly, it will make the outlet area between ribs increase, and the velocity of the air flow is too low so that the air flow on the heat sink ribs is completely affected by the
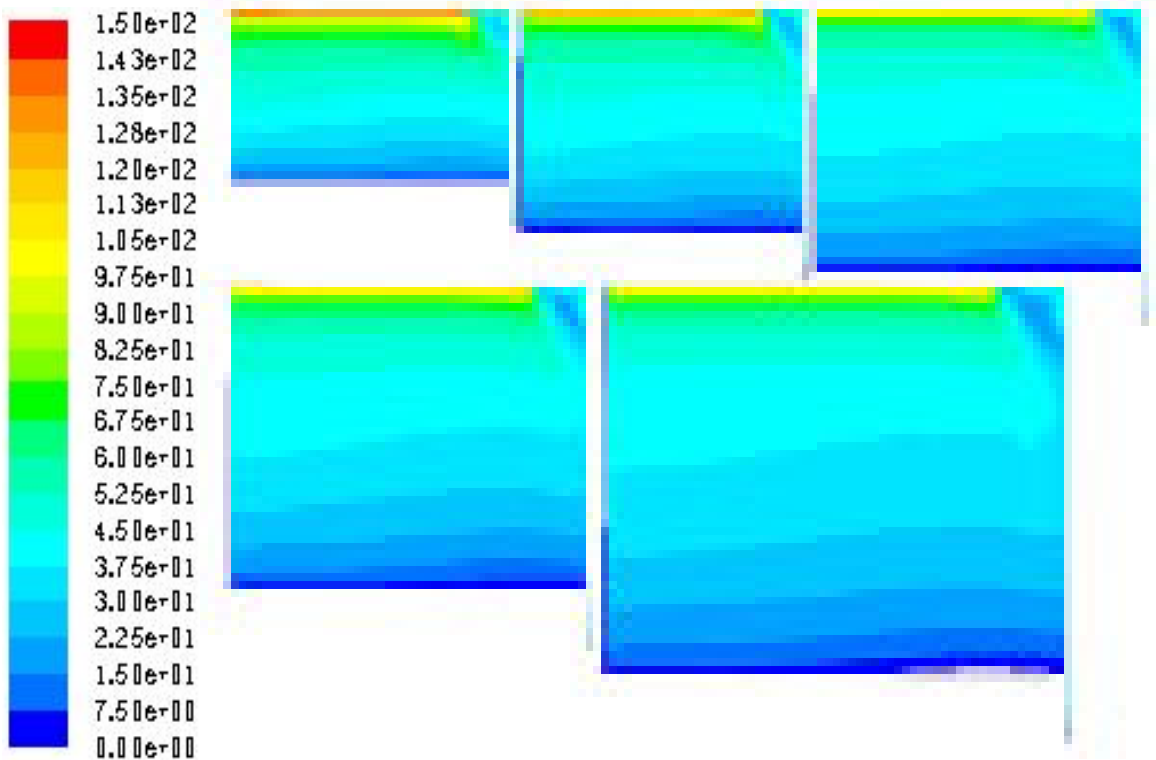

Fig. 10 The distribution of surface convective heat transfer coefficient accompanied by the rib height from small to large

Table 2 Numerical simulation results with different rib heights

\begin{tabular}{|c|c|c|c|c|c|}
\hline Rib height $(\mathrm{mm})$ & 24 & 28 & 32 & 36 & 40 \\
\hline Surface heat transfer coefficient $\left(\mathrm{w} \cdot \mathrm{m}^{-2} \cdot \mathrm{k}^{-1}\right)$ & $0-142.5$ & $0-127.5$ & $0-123.5$ & $0-112.5$ & $0-105$ \\
\hline Average surface heat transfer coefficient $\left(\mathrm{w} \cdot \mathrm{m}^{-2} \cdot \mathrm{k}^{-1}\right)$ & 46.74 & 41.94 & 37.91 & 34.85 & 32.16 \\
\hline The highest temperature in the solid region $(\mathrm{K})$ & 312.43 & 312.38 & 312.06 & 311.94 & 311.84 \\
\hline The average temperature of the heating surface $(\mathrm{K})$ & 311.94 & 311.88 & 311.56 & 311.45 & 311.35 \\
\hline The average temperature of the rib base surface $(\mathrm{K})$ & 310.67 & 310.6 & 310.28 & 310.16 & 310.07 \\
\hline The average temperature of air flow $(\mathrm{K})$ & 303.2 & 303.21 & 303.22 & 303.26 & 303.28 \\
\hline$m$ & 24.03 & 22.76 & 21.64 & 20.75 & 19.93 \\
\hline $\operatorname{Rib}$ efficiency $\left(\eta_{f}\right)$ & 90.21 & 88.35 & 86.58 & 84.79 & 83.1 \\
\hline
\end{tabular}



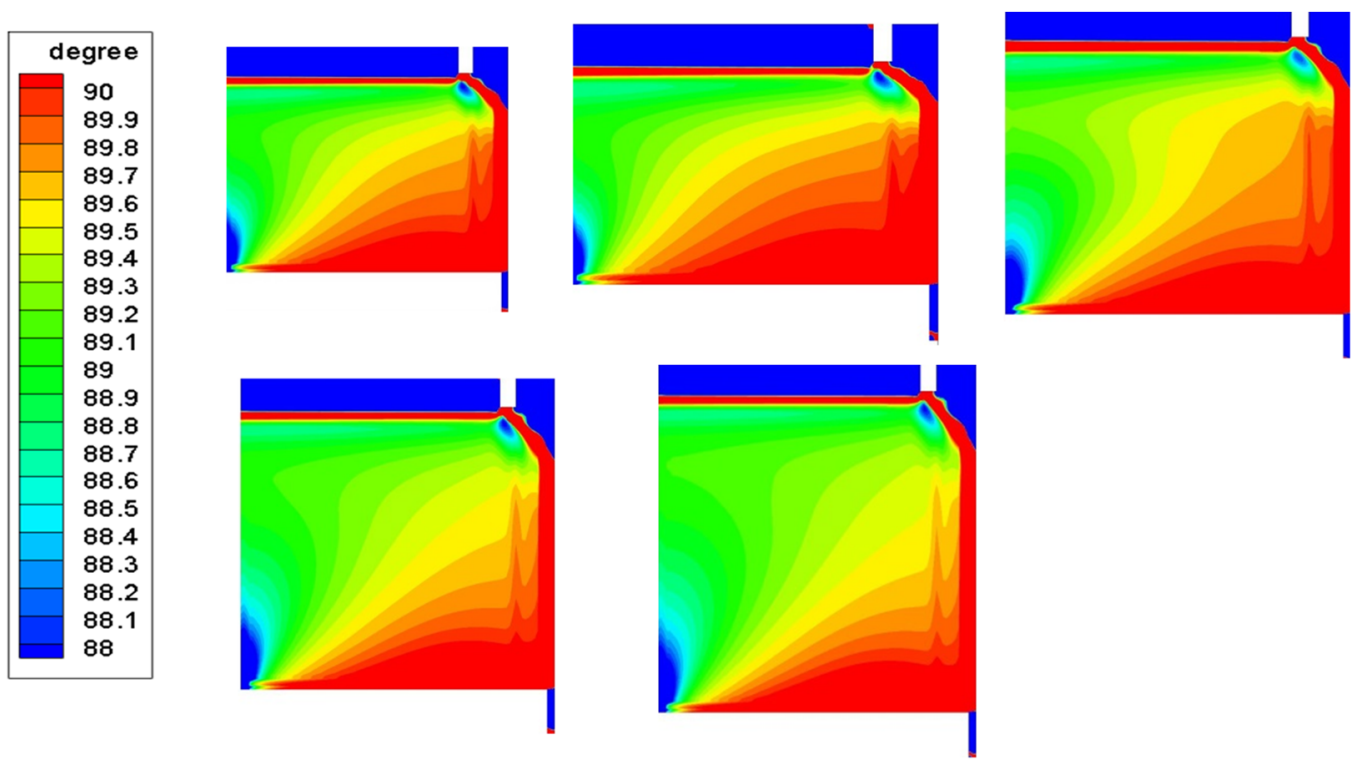

Fig. 11 Contour of field synergy angle for different rib height

ambient air flow, even hindered effect. Fourthly, if ribs are too high in a chassis, it will have a negative impact on the convection within the chassis, and affect the heat dissipation on other components.

Figure 11 shows the distribution of field synergy angles in the fluid domain when rib height is $24 \mathrm{~mm}, 28 \mathrm{~mm}, 32 \mathrm{~mm}, 36 \mathrm{~mm}$, and $40 \mathrm{~mm}$, respectively. It can be seen that the synergy angles will increase with the increase of rib height. The average field synergy angle corresponding to the different rib height is $75.35^{\circ}, 76.96^{\circ}$ and $78.51^{\circ} 79.03^{\circ}$ and $79.86^{\circ}$ respectively. The increase of the fin height will reduce the field synergy between the flow and heat transfer in the fluid domain, and the decrease of coordination also reduced the average convection heat transfer coefficient and reduced the intensity of heat dissipation.. The analysis of field synergy is also consistent with the results of the previous thermal analysis.

\section{CONCLUSION}

The field synergy principle and thermal resistance analysis for the enhancement of air-cooling based heat sink of CPU is investigated in this paper. Thermal analysis of the heat dissipation capacity is applied for setting up the gallery on the rib, changing the fan ventilation diameter and changing the rib height. The results show that:

(1) the analysis of field synergy principle agrees well with the thermal analysis;

(2) setting up the gallery on ribs can improve the heat dissipation capacity of the chip heat sink;

(3) decreasing ventilation diameter leads to the decrease of the radiating capacity, and the reason of which is the increase of the reflow area and the reduction of the air flow;

(4) the change of the rib height directly leads to the change of the geometric parameters of the flow channel, which has a significant effect on the surface convective heat transfer coefficient. Therefore, this factor should be considered when we design the rib height. In addition, many heat sinks are designed by increasing the number of ribs to increase the heat dissipation area. In the premise of the airflow resistance to meet requirements, improving the rib efficiency and surface convection coefficient are better than only increasing the rib height.

\section{ACKNOWLEDGEMENT}

Financial support from the China Scholarship Council, the Science Development Project of the University of Shanghai for Science and Technology, and the National Natural Science Foundation of China under grants number 51306120 are gratefully acknowledged.

\section{NOMENCLATURE}

\begin{tabular}{|c|c|}
\hline$A_{c}$ & The rib cross-sectional area $\left(\mathrm{m}^{2}\right)$ \\
\hline $\mathrm{C}_{\mu} \mathrm{C}_{1} \mathrm{C}_{2}$ & Constant \\
\hline$c_{p}$ & Specific heat of air $\left(\mathrm{kJ} \cdot \mathrm{kg}^{-1} \mathrm{~K}^{-1}\right)$ \\
\hline$g$ & Acceleration constant due to gravity $\left(\mathrm{m} \cdot \mathrm{s}^{-2}\right)$ \\
\hline$h$ & The surface convection heat transfer coefficient $\left(\mathrm{W} \cdot \mathrm{m}^{-2} \cdot \mathrm{K}^{-1}\right)$ \\
\hline$k$ & Turbulent kinetic energy \\
\hline$p$ & Pressure of air $(\mathrm{Pa})$ \\
\hline $\mathrm{Nu}_{x}$ & Local Nusselt number \\
\hline $\operatorname{Pr}$ & Prandtl number \\
\hline $\mathrm{R}$ & Thermal resistance $\left(\mathrm{K} \cdot \mathrm{kW}^{-1}\right)$ \\
\hline $\operatorname{Re}_{x}$ & Local Reynolds number \\
\hline$Q$ & The rate of heat transfer $(\mathrm{kW})$ \\
\hline$T$ & Temperature $(\mathrm{K})$ \\
\hline$t$ & Node temperature $(\mathrm{K})$ \\
\hline$u$ & Velocity component in the $\mathrm{x}$-direction $\left(\mathrm{m} \cdot \mathrm{s}^{-1}\right)$ \\
\hline$v$ & Velocity component in the $y$-direction $\left(\mathrm{m} \cdot \mathrm{s}^{-1}\right)$ \\
\hline $\bar{U}$ & Dimensionless velocity \\
\hline \multicolumn{2}{|c|}{ Greek Symbols } \\
\hline$\beta$ & Field Synergy Angle(rad) \\
\hline$\Gamma$ & Thermal diffusion coefficient \\
\hline$\varepsilon$ & Tturbulent kinetic energy dissipation rate \\
\hline$\eta$ & The kinetic viscosity $(\mathrm{Pa} \bullet \mathrm{s})$ \\
\hline$\eta_{f}$ & Rib efficiency \\
\hline$\lambda$ & Thermal conductivity $\left(\mathrm{W} \cdot \mathrm{m}^{-1} \cdot \mathrm{K}^{-1}\right)$ \\
\hline$\sigma_{z}$ & Thickness of thermal boundary layer (m) \\
\hline$\rho$ & Density of air $\left(\mathrm{kg} \cdot \mathrm{m}^{-3}\right)$ \\
\hline$\phi$ & Heat flux $\left(\mathrm{kW} \cdot \mathrm{m}^{-2}\right)$ \\
\hline \multicolumn{2}{|c|}{ Subscripts } \\
\hline a & Air \\
\hline s & Rib \\
\hline
\end{tabular}




\section{REFERENCES}

Ahmed, H.E., 2016, "Optimization of Thermal Design of Ribbed FlatPlate Fin Heat Sink," Applied Thermal Engineering, 102, 1422-1432. http://dx.doi.org/10.1016/j.applthermaleng.2016.03.119

Baby, R. and Balaji, C., 2013, "Thermal Optimization of PCM Based Pin Rib Heat Sinks: An Experimental Study," Applied Thermal Engineering, 54(14), 65-77.

http://dx.doi.org/10.1016/j.applthermaleng.2012.10.056

Bejan, A and Sciubba, E., 1992, "The Optimal Spacing of Parallel Plates Cooled by Forced Convection," International Journal of Heat and Mass Transfer, 35(12), 3259- 3264.

http://dx.doi.org/10.1016/0017-9310(92)90213-C

Bessaih, R. and Kadja, M., 2000, "Turbulent Natural Convection Cooling of Electronic Components Mounted on a Vertical Channel," Applied Thermal Engineering, 20, 141-154.

http://dx.doi.org/10.1016/S1359-4311(99)00010-1

Chen, C. T. and Chen, H.I., 2013, "Multi-objective Optimization Design of Plate-rib Heat Sinks Using a Direction-based Genetic Algorithm," Journal of the Taiwan Institute of Chemical Engineers, 44(2), 257-265. http://dx.doi.org/10.1016/j.jtice.2012.11.012

Etemoglu, A.B., 2007, “A Brief Survey and Economical Analysis of Air Cooling for Electronic Equipments," International Communications in Heat and Mass Transfer, 34, 103-113.

http://dx.doi.org/10.1016/j.icheatmasstransfer.2006.08.005

Ghasemi, S.E., Ranjbar, A.A. and Hosseini, M.J., 2017, "Experimental and Numerical Investigation of Circular Mini-channel Heat Sinks with Various Hydraulic Diameter for Electronic Cooling Application," Microelectronics Reliability, 73, 97-105.

http://dx.doi.org/10.1016/j.microrel.2017.04.028

Guo, Z.Y., 2000, "Physical Mechanism and Control of Convective Heat Transfer: Synergy Between Velocity Field and Heat Flow Field," Chinese Science Bulletin, 45(19), 2118-2122. (in Chinese)

Guo, Z.Y., Tao, W.Q. and Shah, R.K., 2005, "The Field Synergy (Coordination) Principle and Its Applications in Enhancing Single Phase Convective Heat Transfer," International Journal of Heat and Mass Transfer, 48, 1797-1807.

http://dx.doi.org/10.1016/j.ijheatmasstransfer.2004.11.007

Huang, S., Zhao, J. and Gong, L., 2017, "Thermal Performance and Structure Optimization for Slotted Micro-channel Heat Sink," Applied Thermal Engineering, 115, 1266-1276.

http://dx.doi.org/10.1016/j.applthermaleng.2016.09.131

Joo, Y., Lee, I. and Kim, S.J., 2017, “Topology Optimization of Heat Sinks in Natural Convection Considering the Effect of Shape-dependent Heat Transfer Coefficient," International Journal of Heat and Mass Transfer, 109, 123-133.

http://dx.doi.org/10.1016/j.ijheatmasstransfer.2017.01.099
Knight, R.W., Hall, D.J. and Goodling, J.S., 1992, "Heat Sink Optimization with Application to Microchannels," IEEE Transactions on Evolutionary Computation, 15(5), 832-842.

http://dx.doi.org/10.1109/33.180049

Levin, P.P., Shitzer, A. and Hetsroni, G., 2013, "Numerical Optimization of a PCM-based Heat Sink with Internal Fins," International Journal of Heat and Mass Transfer, 61, 638-645.

http://dx.doi.org/10.1016/j.ijheatmasstransfer.2013.01.056

Meng, J.A., 2003, "Longitudinal Vortex Enhanced Heat Transfer Technology Based on Field Synergy Theory and Its Application [Ph.D. Thesis]," Tsinghua University, Beijing. (in Chinese)

Mohan, R. and Govindarajan, P., 2011, "Experimental and CFD Analysis of Heat Sinks with Base Plate for CPU Cooling," Journal of Mechanical Science and Technology, 25(8), 2003-2012.

http://dx.doi.org/10.1007/s12206-011-0531-8

Naphon, P., Klangchart, S. and Wongwises, S., 2009, "Numerical Investigation on the Heat Transfer and Flow in the Mini-rib Heat Sink for CPU," International Communications in Heat and Mass Transfer, 36(8), 834-840.

http://dx.doi.org/10.1016/j.icheatmasstransfer.2009.06.010

Naphon, P. and Wiriyasart, S., 2009, "Liquid Cooling in the Minirectangular Rib Heat Sink with and without Thermoelectric for CPU," International Communications in Heat and Mass Transfer, 36(2), 166171.

http://dx.doi.org/10.1016/j.icheatmasstransfer.2008.10.002

Ozturk, E. and Tari, I., 2008, "Forced Air Cooling of CPUs with Heat Sinks: a Numerical Study," IEEE Transaction on Components and Packaging Technologies, 31(3), 650-660.

http://dx.doi.org/10.1109/TCAPT.2008.2001840

Versteeg, H.K. and Malalasekera, W., 1995, "An Introductionto Computational Fluid Dynamics: The Finite Volume Method," England: Longman Group LMD.

Yamamoto, T., Kuwahara, T. and Yoshino, K., 2014, "Numerical Investigation of Cooling Characteristics for Fine Mist Cooling of High Temperature Material," Computational Thermal Sciences, 6(1), 69-78. http://dx.doi.org/10.1615/ComputThermalScien.2014005831

Yang, J., Li, L. and Yang, L., 2017, "Uniform Design for the Parameters Optimization of Pin-fins Channel Heat Sink," Applied Thermal Engineering, 120, 289-297.

http://dx.doi.org/10.1016/j.applthermaleng.2017.03.122

Yang, Y.T. and Peng, H.S., 2008, "Numerical Study of Pin-rib Heat Sink with Un-uniform Rib Height Design," International Journal of Heat and Mass Transfer, 51(19-20), 4788-4796.

https://doi.org/10.1016/j.ijheatmasstransfer.2008.02.017

Yang, S.M. and Tao, W.Q., 2006, "Heat Transfer," Beijing: High Education Press. (in Chinese) 